\title{
Total Chlorine-Free Bleaching of Populus deltoides Kraft Pulp by Oxone
}

\author{
Mohsen Miri, ${ }^{1}$ Ali Ghasemian, ${ }^{1}$ Hosein Resalati, ${ }^{1}$ and Farhad Zeinaly ${ }^{2}$ \\ ${ }^{1}$ Department of Pulp \& Paper Industries, Faculty of Wood \& Paper Engineering, \\ Gorgan University of Agricultural Sciences and Natural Resources, Gorgan 49175-487, Iran \\ ${ }^{2}$ Young Researchers and Elite Club, Islamic Azad University, Karaj Branch, Karaj 31485-313, Iran
}

Correspondence should be addressed to Farhad Zeinaly; farhad.zeinaly@yahoo.com

Received 19 May 2015; Revised 30 July 2015; Accepted 30 July 2015

Academic Editor: J. F. Vliegenthart

Copyright (C) 2015 Mohsen Miri et al. This is an open access article distributed under the Creative Commons Attribution License, which permits unrestricted use, distribution, and reproduction in any medium, provided the original work is properly cited.

\begin{abstract}
Since the bleaching process is one of the most important environmental pollutant stages in the pulp and paper industry, here, the total chlorine-free (TCF) bleaching of poplar kraft pulp by applying Oxone and peroxide under alkaline conditions has been investigated. The pulp samples were bleached in two stages of Oxone $\left(\mathrm{O}_{\mathrm{X}}\right)$ treatment using an $\mathrm{AO}_{\mathrm{X} 1} \mathrm{O}_{\mathrm{X} 2}$ sequence $(\mathrm{A}$ : acid pretreatment), and then the treated pulps were bleached by peroxide (P) to achieve target brightness (about $80 \%)$. The influence of various reaction parameters such as alkali charge, temperature, reaction time, and bleaching agent dosage was optimized. The final achieved brightness was more than 78\%. Accelerated aging experiments showed more stability in brightness for the Oxone treated pulp, because alkali Oxone bleaching stops thermal degradation. Similarly, the $\mathrm{AO}_{\mathrm{x}_{1}} \mathrm{O}_{\mathrm{X} 2} \mathrm{P}$ bleaching sequence was found to be effective in regaining some strength that had been lost during acidification of the pulp. Improvement in pulp strength made with acid treatment was achieved along with significant amount of lignin removal and it demonstrates the feasibility of Oxone in TCF bleaching. Furthermore, other results indicated the feasibility of Oxone bleaching as an environmentally favorable alternative TCF bleaching sequence, compared with elemental chlorine-free bleaching approaches and also other TCF bleaching sequences.
\end{abstract}

\section{Introduction}

The increasing demand for high quality paper and paper products places a great strain on sources such as cellulosic raw material, energy, and chemicals. In recent years, the pulp and paper industry has faced market requirement, as well as environmental pressures, because, historically, production of pulp and paper has been recognized as a significant point in the environmental pollution [1]

The bleaching process has been commonly known as an important environmental pollutant stage in the pulp and paper industry. Up to now, chlorine and chlorinated compounds have been categorized as the important chemicals being used in this process. However, the search for environmentally friendly methods of pulp bleaching has led to the development of nonchlorine bleaching techniques, in recent decades. Utilizing different chemical agents has been examined as appropriate delignification in previous studies [2].
Total chlorine-free (TCF) bleaching process has been introduced in response to environmental restrictions and market demand for non-chlorine-based chemical bleached pulp [3]. This resulted in the development of TCF bleaching technologies by applying oxygen, hydrogen peroxide, ozone, and peracetic acid in bleaching sequence. A worldwide TCF bleaching increase was expected, but at the present TCF bleaching process is used in just a few companies [4].

In 2010, production of TCF bleached pulp accounted for only $5 \%$ of the total bleached pulp production worldwide (Annual Report by the Alliance for Environmental Technology, 2010). This low market uptake of TCF bleaching can be explained by a higher bleaching cost, lower final pulp strength, less hexenuronic acid removal, and more brightness reversion in comparison with ECF (Elemental ChlorineFree) bleached pulp.

Current exotic chemicals that are used in various bleaching sequences include peroxyacetic acid [5], peroxyformic 
acid [5], potassium peroxymonosulfate (Oxone) [5, 6], potassium peroxymonophosphoric acid [7], and dimethyl dioxiranes [8].

Oxone is a white, granular compound, which provides powerful nonchlorine oxidation for a wide variety of industrial and nonindustrial usages. The active part of Oxone is potassium peroxymonosulfate $\left(\mathrm{KHSO}_{5}\right)$, which is commonly known as potassium monopersulfate. This complex is a component of a triple salt with the following formula: $2 \mathrm{KHSO}_{5} \cdot \mathrm{KHSO}_{4} \cdot \mathrm{K}_{2} \mathrm{SO}_{4}$. The oxidizing power of Oxone is derived from its peracid chemistry; it is the first neutralization salt of peroxymonosulfuric acid $\mathrm{H}_{2} \mathrm{SO}_{5}$ also known as Caro's acid [9].

The ability of acidic peroxymonosulfate solutions in appropriate delignification has proven their usage in pulping and bleaching. These solutions might be used for wood treatment or other lignocellulosic materials to produce a variety of chemical pulps. Also, peroxymonosulfate might be used as substitute for chlorine and dioxide chlorine in the pulp bleaching and/or as a pretreatment prior to oxygen bleaching $[10,11]$.

It is important for the countries with low natural forest such as Iran to utilize fast growing nonforest wood species in pulp and paper production. Populus deltoides is one of the fastest growing nonforest species as it is well adapted to the Iranian climate, especially in humid and semiarid regions [12]. This species was used in this study for producing bleached kraft pulp by using environmental friendly processes (TCF bleaching process).

In this study, kraft poplar pulp underwent acid pretreatment by sulphuric acid and then bleached by aqueous solutions of Oxone at alkaline conditions. Oxone is one of the most selective bleaching chemicals and, therefore, two stages of bleaching sequence $\mathrm{AO}_{\mathrm{X} 1} \mathrm{O}_{\mathrm{X} 2}$ were designed after optimizing the amount of Oxone charge $\left(\mathrm{O}_{\mathrm{X}}\right)$, alkali charge, temperature, and reaction time. Finally, a hydrogen peroxide bleaching stage was evaluated as the final brightening stage at the end of each sequence. The effect of bleaching process on optical, mechanical, and chemical properties of bleached pulp was studied.

\section{Materials and Methods}

2.1. Materials. The solution of Oxone (potassium peroxymonosulfate), obtained from Merck Co., was prepared by dissolving in distilled water. Kraft poplar pulp from Populus deltoids was produced in pulp and paper laboratories of Gorgan University, Iran. The pulp was screened through a 20 mesh screen to remove shives and then stored at $4^{\circ} \mathrm{C}$, for the course of the bleaching experiments to minimize any changes in pulp properties. The kappa number (the kappa number is an indication of the lignin content or bleachability of pulp) of the unbleached Kraft pulp was 15.3, the degree of polymerization was 1796, and ISO brightness was (R457) $22.38 \%$.

\subsection{Methods}

2.2.1. Acid Pretreatment Stage (A). A simple process to eliminate transition metals is a single stage treatment of pulp
TABle 1: Pulp metal contents.

\begin{tabular}{lcccc}
\hline & $\mathrm{Fe}$ & $\mathrm{Mg}$ & $\mathrm{Cu}$ & $\mathrm{Mn}$ \\
\hline Initial pulp & 1.324 & 2.615 & 0.123 & 0.166 \\
Acidified pulp & 1.040 & 2.608 & 0.078 & 0.142 \\
\hline
\end{tabular}

at the acidic $\mathrm{pH}$ of 3-4 [13]. The pulp was acidified up to about pH 3.5 with $\mathrm{H}_{2} \mathrm{SO}_{4}$ solution $(4.0 \mathrm{~N})$ at a $10 \%$ pulp consistency for 10 minutes in room temperature to remove pulp metal ions. After acidification, the pulp was washed with distilled water. The metal contents ( $\mathrm{Fe}, \mathrm{Mg}, \mathrm{Mn}$, and $\mathrm{Cu}$ ) of the acidified washed pulp were determined by the method of flame atomic absorption spectrophotometry (Shimadzo AA7000).

2.2.2. Oxone Bleaching $\left(O_{X}\right)$. Pulp samples from acid pretreatment were bleached at different concentrations of Oxone under aqueous alkaline conditions at $10 \%$ pulp consistency in polythene zip locking bags for 60 minutes at $65^{\circ} \mathrm{C}$. Some of the used conditions for the bleaching stage by Oxone had been selected based on previous studies [14]. After each Oxone treatment the pulp samples were washed with distilled water to neutralize the $\mathrm{pH}$.

2.2.3. Peroxide Bleaching $(P)$. Peroxide bleaching stage was designed as the final brightening stage at the end of each sequence. The treated pulp was bleached with hydrogen peroxide to achieve target brightness (about $80 \%$ ISO). The peroxide bleaching conditions were as follows: $3 \%$ peroxide charge, $3 \%$ sodium silicate, $0.3 \%$ DTPA, $1.5 \% \mathrm{NaOH}, 10 \%$ pulp consistency, $90^{\circ} \mathrm{C}$ temperature, and 60 -minute reaction time (all chemicals are based on oven dried pulp).

2.2.4. Physical Testing. Hand sheets were prepared according to the standard of TAPPI T205-sp-02 and left to be conditioned for $24 \mathrm{hrs}$ prior to testing. An Elrepho 2000 spectrophotometer was used to measure the brightness, R457 (T 452 om-98), of the hand sheets. Accelerated ageing ISO 5630-1 method was used to test the brightness stability of bleached samples by dry heating at $105^{\circ} \mathrm{C}$ for $24 \mathrm{hrs} \pm$ $10.0 \mathrm{~min}$. The burst and tear strength of hand sheets were determined according to the standard of TAPPI T414 om-04 and T403 om-02, respectively.

2.2.5. Chemical Testing. The kappa number and the degree of polymerization of the samples were determined according to the standard of TAPPI T 236 om-99 and T 230 Om-94. The COD load of filtrate samples was measured by ISO 6060 method.

\section{Results and Discussion}

3.1. Acid Pretreatment Stage. Acid pretreatment is performed to remove metal ions out of the pulp and to improve the performance of bleaching chemicals $[13,15]$. The metal contents of the pulp are given in Table 1, before and after acid pretreatment. The results showed that the acid pretreatment 
TAble 2: Pulp properties after Oxone bleaching stages.

\begin{tabular}{|c|c|c|c|c|c|c|c|c|c|}
\hline \multirow[t]{2}{*}{ Bleaching sequences } & \multicolumn{2}{|c|}{$\begin{array}{c}\mathrm{O}_{\mathrm{X}}(\%) \\
\text { in different stages }\end{array}$} & \multicolumn{2}{|c|}{$\begin{array}{c}\mathrm{NaOH}(\%) \\
\text { in different stages }\end{array}$} & \multicolumn{2}{|c|}{$\mathrm{pH}$} & \multirow[t]{2}{*}{$\begin{array}{l}\text { Yield } \\
(\%)\end{array}$} & \multirow[t]{2}{*}{ Kappa number } & \multirow[t]{2}{*}{ Brightnes } \\
\hline & 1 st & 2nd & 1 st & 2nd & Initial & Final & & & \\
\hline $\mathrm{AO}_{\mathrm{X}}$ & 1 & - & 0.5 & - & 9.50 & 7.10 & 97.9 & 12.45 & 31.17 \\
\hline $\mathrm{AO}_{\mathrm{X}}$ & 3 & - & 1.5 & - & 10.74 & 8.34 & 97.1 & 8.85 & 37.43 \\
\hline $\mathrm{AO}_{\mathrm{X}}$ & 5 & - & 2.5 & - & 11.12 & 8.50 & 97.0 & 7.86 & 40.02 \\
\hline $\mathrm{AO}_{\mathrm{X}}$ & 7 & - & 3.5 & - & 11.35 & 9.15 & 96.6 & 7.65 & 39.91 \\
\hline $\mathrm{AO}_{\mathrm{X}}$ & 10 & - & 5.0 & - & 11.71 & 9.02 & 96.6 & 4.86 & 48.81 \\
\hline $\mathrm{AO}_{\mathrm{X} 1} \mathrm{O}_{\mathrm{X} 2}$ & 3 & 3 & 1.5 & 1.5 & 10.56 & 7.90 & 95.3 & 4.94 & 46.97 \\
\hline $\mathrm{AO}_{\mathrm{X} 1} \mathrm{O}_{\mathrm{X} 2}$ & 5 & 5 & 2.5 & 2.5 & 12.05 & 9.52 & 93.7 & 3.50 & 54.91 \\
\hline
\end{tabular}

caused a decrease in metal contents, but in different rates. $\mathrm{Mg}$ was the most prevalent metal ion and $\mathrm{Cu}$ was the least. The maximum removal rates are, respectively, related to $\mathrm{Fe}, \mathrm{Cu}$, $\mathrm{Mn}$, and $\mathrm{Mg}$ ions.

Also, the kappa number decreased approximately one unit and the brightness increased about two units by performing stage A (acid pretreatment). This could be due to removal of Hex.A groups, which are created in the alkaline kraft pulping. During kraft pulping a considerable amount of 4-O-methyl-D-glucuronic acid residues (MeGlcA) in xylan hemicelluloses is converted into 4-deoxy-4-enuronic acid (hexenuronic acid) groups. Because of its unsaturated moiety, Hex.A groups consume some of the bleaching reagents; thus the efficiency of pulp bleaching is decreased. The remaining Hex.A groups in bleached pulps influence their brightness stability negatively [16]. For these reasons, the Hex.A removal in kraft pulps by acid pretreatment has been proven to be an essential stage. The Hex.A contents of untreated and acid treated pulps were, respectively, 57.4 and 24.6. Thus, chemical treatment with $\mathrm{H}_{2} \mathrm{SO}_{4}$ can help the selective removal of Hex.A groups.

3.2. Oxone Stage Optimization. For the Oxone stage, some experiments (including optimization of alkali charge, temperature, reaction time, and bleaching agent dosage) were conducted to determine the optimum number of bleaching stages for achieving the maximum brightness with the use of Oxone. The results show that the double-stage Oxone bleaching $\left(\mathrm{AO}_{\mathrm{X} 1} \mathrm{O}_{\mathrm{X} 2}\right)$ had higher brightness value of $54.91 \%$ ISO compared to $40.02 \%$ ISO which was achieved by a single bleaching stage of Oxone (Table 2). The kappa number decreased significantly by two stages of Oxone bleaching. According to the literature, performing Oxone bleaching stage more than twice had a slight improving impact on the brightness [6].

After achieving the optimum Oxone charge, the effects of alkaline charge and bleaching conditions (temperature and reaction time) were studied in order to determine an appropriate condition to maximize the brightness in each stage of the double-stage bleaching sequence. Figure 1(a) indicates that increasing the alkali $(\mathrm{NaOH})$ charge to $3.5 \%$ resulted in a significant increase in brightness, from 31.7 to $46.5 \%$ ISO.
The effect of reaction temperature was studied by using the optimum alkali charge (3.5\%). Brightness was found to increase up to $47.3 \%$ ISO when the pulp was heated to $65^{\circ} \mathrm{C}$ as shown in Figure 1(b). Temperatures above $65^{\circ} \mathrm{C}$ did not have any effect on the brightness.

Also, the effect of the reaction time was studied at 3.5\% $\mathrm{NaOH}$ and $65^{\circ} \mathrm{C}$. The results in Figure 1(c) showed that pulp brightness was increased as bleaching time increased up to 75 minutes and it did not have any significant change at higher reaction times. The optimal conditions determined during the first stage of bleaching experiments (5\% Oxone, $3.5 \% \mathrm{NaOH}, 65^{\circ} \mathrm{C}$, and 75-minute bleaching time) were used to prepare the pulp for the second stage of bleaching experiments. The maximum brightness of $50.0 \%$ ISO was achieved in the first stage of bleaching by Oxone.

The alkali charge, temperature, and reaction time were examined in the second stage to determine the optimal bleaching conditions at a 5\% Oxone charge. Figure 1(d) shows that the second stage needed less alkali charge compared to the first. Increasing alkali $(\mathrm{NaOH})$ charge to $2.5 \%$ resulted in a considerable increase in the pulp brightness. Temperature and reaction time were similar in the first and second stages as shown in Figures 1(e) and 1(f). Overall, the optimum conditions for the second-stage bleaching were as follows: $2.5 \% \mathrm{NaOH}$ on o.d. pulp, a temperature of $65^{\circ} \mathrm{C}$, and a reaction time of 75 minutes.

At the end, treated pulp by $\mathrm{AO}_{\mathrm{X} 1} \mathrm{O}_{\mathrm{X} 2}$ was bleached with hydrogen peroxide to achieve the target brightness of about $80 \%$ ISO. The results in Figure 2 indicate that the brightness of $78 \%$ ISO was achieved by using $2 \%$ hydrogen peroxide, and the kappa number decreased to 1.78 levels. The two main advantages of using Oxone as an alternative to hydrogen peroxide were the increase in bleaching efficiency and the decrease in pulp yield loss. Hydrogen peroxide alone has been found to be relatively ineffective for kraft pulp bleaching [17]. Hydrogen peroxide as an oxidizing agent helped to remove residual lignin, prevented pulp from alkaline-darkening, and also enhanced pulp brightness [18]. Moreover, it might be possible to achieve a fully bleached pulp by the use of single or double prestage oxygen delignification at the beginning of the $\mathrm{AO}_{\mathrm{X} 1} \mathrm{O}_{\mathrm{X} 2} \mathrm{P}$ sequence. The range of delignification in this process is normally $35-50 \%$ (double stage up to $70 \%$ ). A low to moderately high brightness (about $85 \%$ ISO) can be obtained by final bleaching with only hydrogen peroxide; 


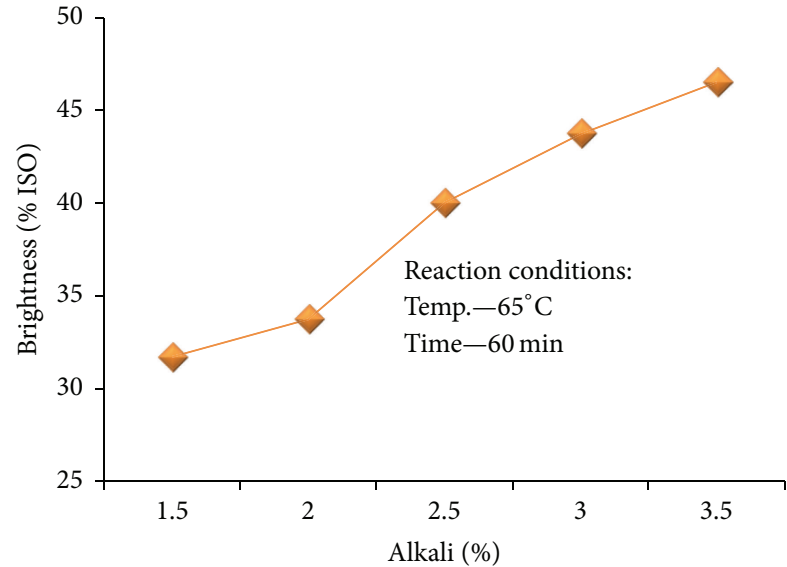

(a)

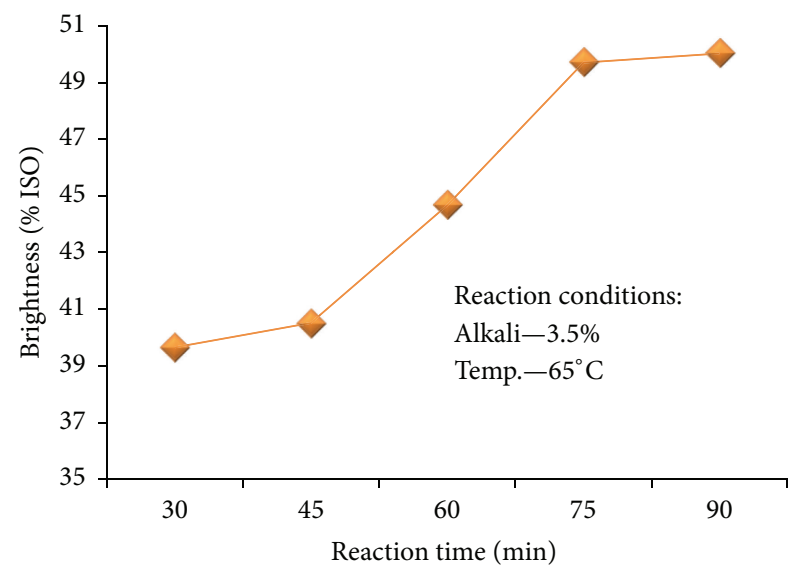

(c)

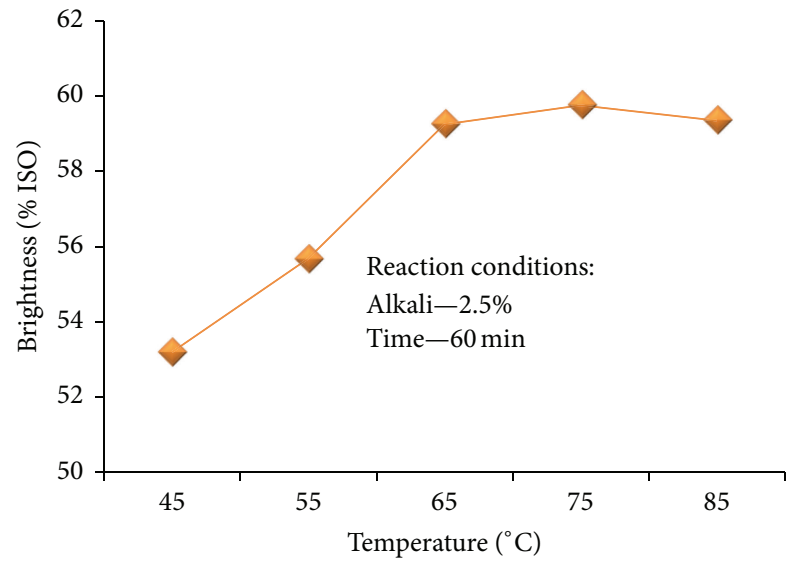

(e)

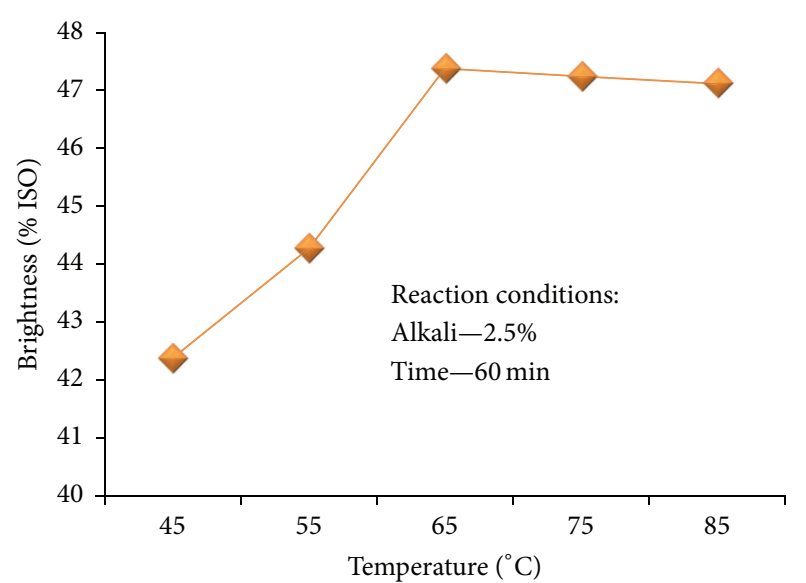

(b)

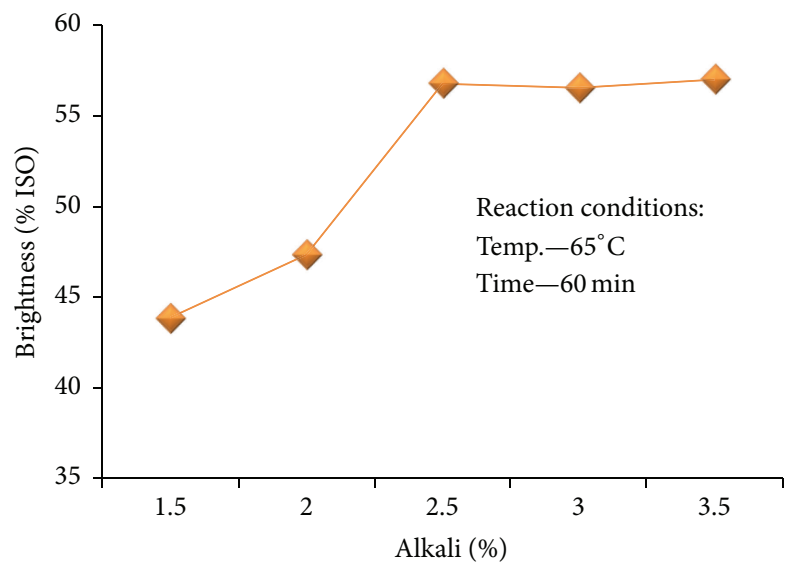

(d)

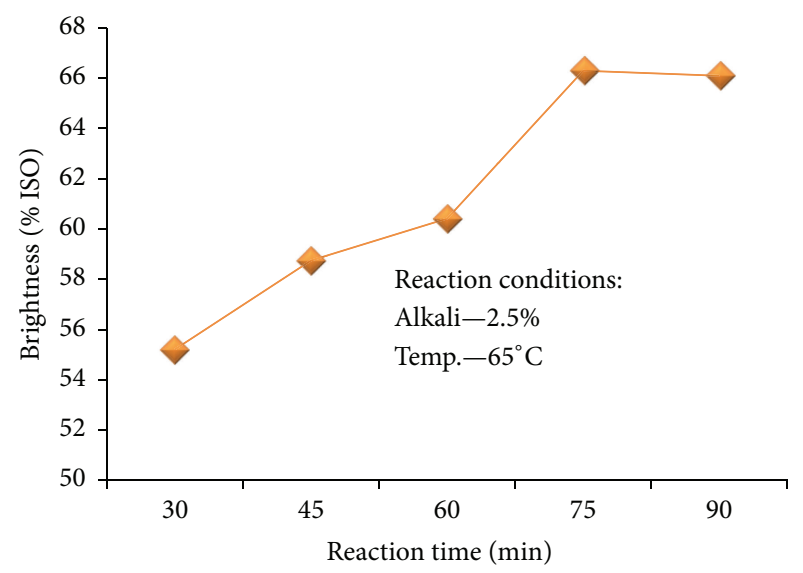

(f)

FIGURE 1: Effect of alkali charge; reaction temperature; reaction time on bleaching response in Oxone first stage bleaching with 5\% Oxone ((a), (b), and (c)) and second-stage bleaching with 5\% Oxone ((d), (e), and (f)). 


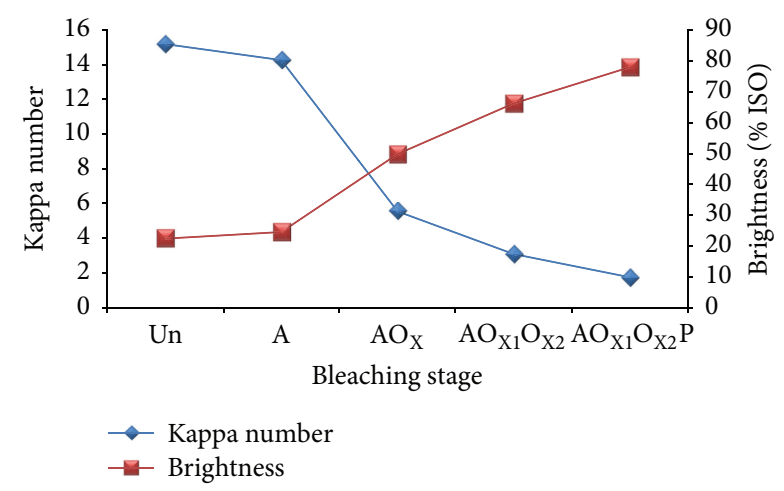

FigURE 2: Effect of bleaching stage on pulp brightness and kappa number.

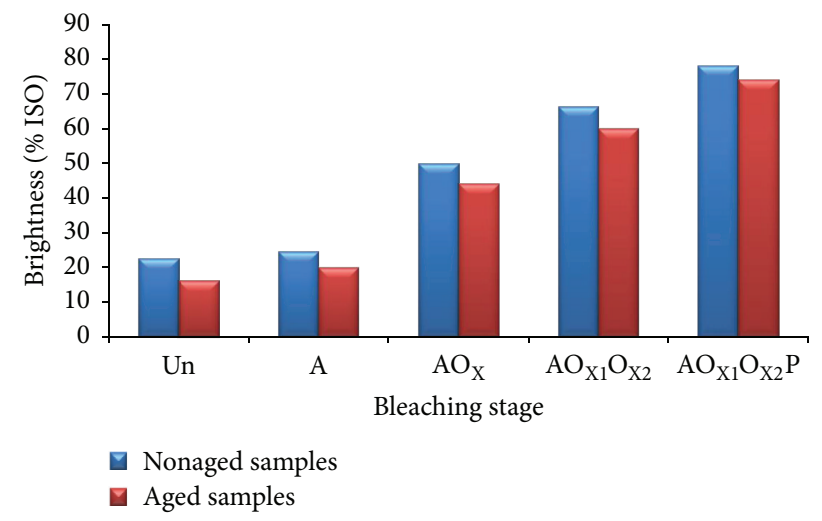

FIGURE 3: Effect of accelerated aging on brightness of pulp from different bleaching sequences.

produced pulp has a kappa number not higher than that corresponding to oxygen delignification. Under favourable conditions, even higher brightness can be achieved [19]. In addition, the ozone can be employed as another strong electrophile bleacher agent for production of fully bleached pulp in TCF sequences.

3.3. Accelerated Aging. One of the flaws of TCF and also ECF bleaching processes is brightness low stability. Although overall brightness reversion is much lower in kraft pulp than that of mechanical pulps, chemical modifications occur due to the bleaching reactions. Some of these reactions can result in the formation or modification of chromophoric groups which enhance the reversion process.

A series of accelerated aging experiments were undertaken on hand sheets which were prepared by various bleaching sequences. Hand sheet samples were exposed to $105^{\circ} \mathrm{C}$ for $24 \mathrm{hrs} \pm 10.0 \mathrm{~min}$ and then their brightness was measured (ISO 5630-1 standard method). The results of heating hand sheets after bleaching showed that a $6 \%$ brightness reversion had occurred after two stages of bleaching with Oxone, Figure 3. A previous study had shown that alkali Oxone bleaching stops thermal degradation (brightness decrease) [20]. A greater decrease in brightness can be explained by

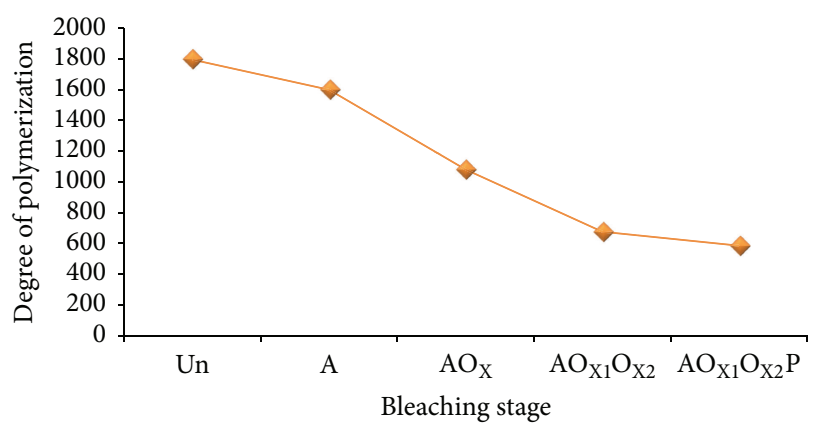

FIGURE 4: Effect of various bleaching stages on degree of polymerization.

residual lignin in the pulp, developing colored groups which contribute to the color reversion.

The final bleaching stage plays an important role in brightness reversion. The results reveal a reduction in the rate of brightness decrease when hydrogen peroxide is used as a final stage. ISO brightness decreased about $4 \%$ in the bleached pulp using the $\mathrm{AO}_{\mathrm{X} 1} \mathrm{O}_{\mathrm{X} 2} \mathrm{P}$ sequence, Figure 3. Previous studies revealed that applying hydrogen peroxide can enhance the final brightness and reduce brightness reversion of pulp [21]. Hydrogen peroxide helps to oxidize carbonyl groups and alkaline decomposition of colorant compounds $[22,23]$.

3.4. Chemical Analysis. The influence of chemical bleaching treatments on residual lignin and cellulose depolymerization was also determined. Mild acid pretreatment reduced the kappa number almost one unit which causes 100-unit drop in the degree of polymerization (D.P). More than $64 \%$ of residual lignin was removed by single stage bleaching $\left(\mathrm{AO}_{\mathrm{X} 1}\right)$ with a kappa number of 5.54. The kappa number of the bleached pulp lessens to about 3 , by performing a second bleaching stage $\left(\mathrm{AO}_{\mathrm{X} 1} \mathrm{O}_{\mathrm{X} 2}\right)$ and applying hydrogen peroxide as final stage of $\mathrm{AO}_{\mathrm{X} 1} \mathrm{O}_{\mathrm{X} 2} \mathrm{P}$ sequence results in a kappa number decrease to 1.75 , Figure 2. Hydrogen peroxide, when used as an oxidizing agent, helped to remove residual lignin and prevented alkaline-darkening therefore, enhancing the brightness [18].

During bleaching process, cellulose chains can be broken. This decrease in molecular mass of the cellulose chains can be studied by measuring pulp polymerization degree. The result shows that a decrease in pulp DP occurred from 1796 to 1600 , in the acidic stage (A). A greater decrease of about $42 \%$ in pulp DP occurred between the first and second Oxone bleaching stage. Also, using peroxide as the final stage in the sequence of $\mathrm{AO}_{\mathrm{X} 1} \mathrm{O}_{\mathrm{X} 2}$ P leads to a smaller decrease in pulp DP (Figure 4).

One of important factors in pulp bleaching is the properties of effluent pollution load. The COD (chemical oxygen demand) loads depend on lignin, carbohydrate, and other dissolved components in the effluent. The more these components are dissolved, the more COD is extended [19]. The result of measuring COD load indicates its negligibility compared to that of the other bleaching chemicals (Figure 5). 


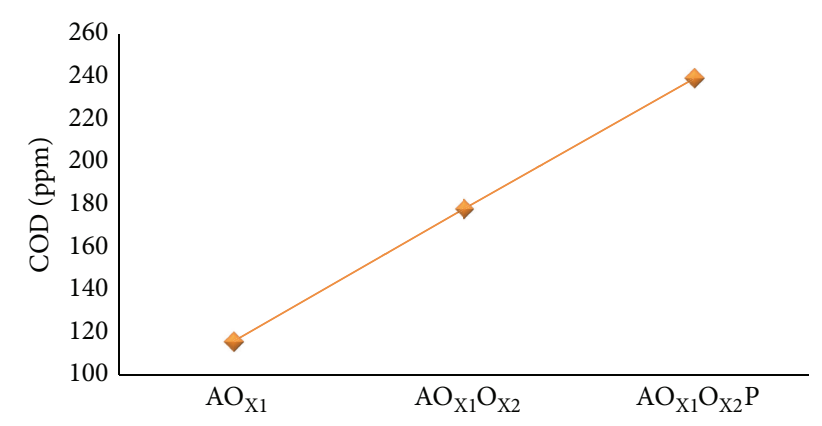

FIGURE 5: Effect of bleaching stages on chemical oxygen demand.

This reveals that the use of $\mathrm{AO}_{\mathrm{X} 1} \mathrm{O}_{\mathrm{X} 2} \mathrm{P}$ sequence could be an environmentally friendly process, because the effluent COD in Oxone bleaching sequences is low; and also adsorbable organic halide (AOX), which is the most crucial fact for any pulp and paper mill, does not emit by this nonchlorine bleaching sequence.

3.5. Mechanical Properties. After the bleaching treatment all pulp samples were refined in a laboratory PFI refiner to reach $350 \mathrm{~mL}$ freeness (Canadian Standard Freeness) for making hand sheets. Then, burst index and tear index were determined for six different hand sheets: unbleached (Un), acidified (A), one stage of Oxone bleaching $\left(\mathrm{AO}_{\mathrm{X} 1}\right)$, two stages of Oxone bleaching $\left(\mathrm{AO}_{\mathrm{X} 1} \mathrm{O}_{\mathrm{X} 2}\right)$, and final stage by peroxide bleaching $\left(\mathrm{AO}_{\mathrm{X} 1} \mathrm{O}_{\mathrm{X} 2} \mathrm{P}\right)$. The results showed that the prepared hand sheets from unbleached kraft poplar pulp have a higher burst index and tear index, Figure 6. Many of the mechanical strengths (e.g., tensile, burst, and tear strength) are dependent on both the bonding strength in the sheet and the strength of individual fibers [24]. Compared to other mechanical strengths such as the tensile and the burst, which are influenced by the quality and quantity of bonding areas, the pulp tear strength is more affected by the strength of individual fibers $[24,25]$. Therefore, the bleaching process has different effects on various mechanical properties, considering the condition. Factually, chemical reactions at intense condition by bleaching agents resulted in fiber collapsibility improvement and more bonding areas; thus, the bonding strength in the sheet increased, and paper bulk decreased [25]. On the other hand, the carbohydrate degradation and alkaline or acid hydrolysis during the bleaching process lead to decrease in the strength of individual fibers [24-26]. Upon acidification at $\mathrm{pH} \mathrm{3.5,} \mathrm{there} \mathrm{is} \mathrm{a} \mathrm{decrease} \mathrm{in} \mathrm{burst}$ index and tear index. A reason for this could be removal of existing hemicelluloses in pulp, because during pretreatment Hex.A groups are converted to acid foeric and 5-carboxy 2formaldehyde [27]. Also, the decrease in carbohydrates DP during acidic treatment (Figure 4) caused decline in pulp strength properties. By adding Oxone to the samples in the first stage of bleaching, the burst index and tear index increased at $3.5 \%$ alkali, $65^{\circ} \mathrm{C}$, and 75 -minute bleaching. Also, an increase was observed in the hand sheets which were prepared from the second-stage pulp of Oxone bleaching at $2.5 \%$ alkali, $65^{\circ} \mathrm{C}$, and 75 minutes. This can be explained

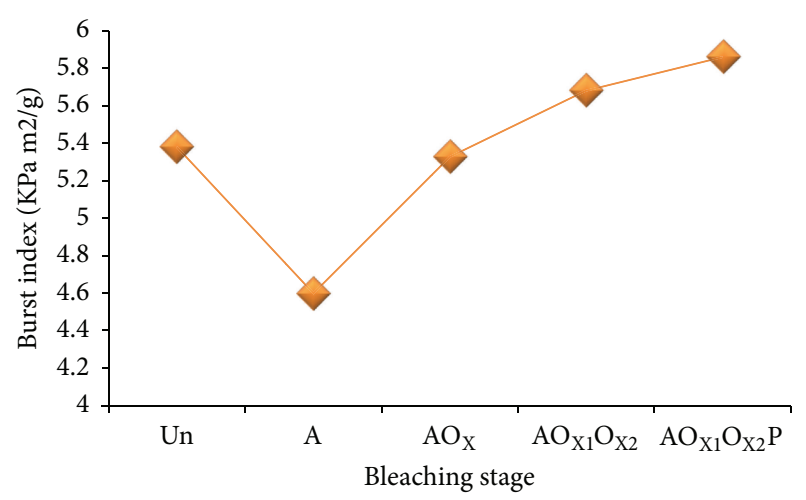

(a)

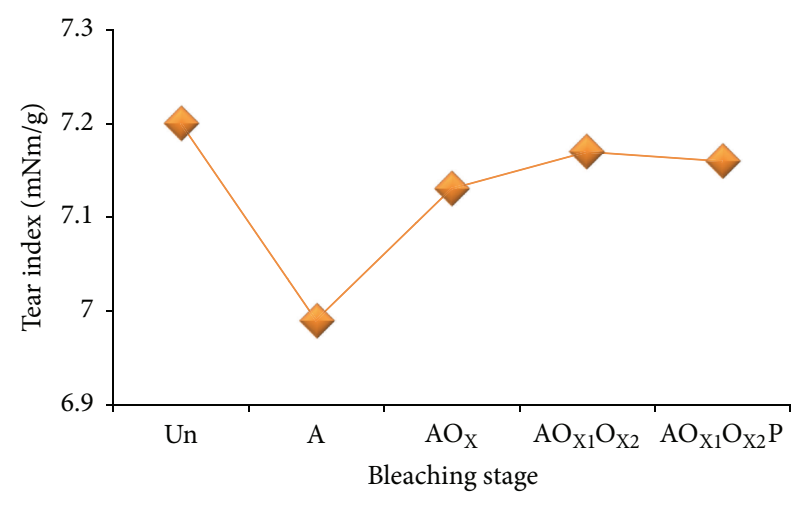

(b)

FIGURE 6: Effect of bleaching stages on the burst and tear indexes of pulp samples.

by alkali condition, which causes fiber walls to open and/or leads to the hydrolyzation of ester bonding between fiber walls. Thus, the water amount increased within the fiber walls, causing swelling, allowing the fiber to gain flexibility. At the end of bleaching, the burst index was slightly increased by applying peroxide, but the tear index slightly decreased. The work of tearing is made up of two processes. One is to stretch fibers until they break, this process being governed by the strength of the individual fibers. The other process is to pull out fibers from the network and this part of the work depends on both breaking of bonds and frictional forces. The energy needed to pull out a fiber from the network is much larger than the energy needed to break a fiber. More bleaching damage of the end $\mathrm{P}$ stage and more cellulose degradation during this process caused making up weak fibers, which led to a decrease in tear strength [24].

\section{Conclusions}

The two stages of Oxone bleaching sequences, after an acid pretreatment stage, and the usage of hydrogen peroxide as final stage of $\mathrm{AO}_{\mathrm{X} 1} \mathrm{O}_{\mathrm{X} 2} \mathrm{P}$ sequence in kraft poplar pulp were found to result in a pulp brightness of more than $78 \%$ ISO. Pulp brightness in the first stage showed an increase while the alkali charge rose to $3.5 \% \mathrm{NaOH}$. Increasing the bleaching temperature up to $65^{\circ} \mathrm{C}$ and reaction time to 75 minutes was 
found to result in the maximum brightness of 50.02\% ISO in the first stage. Similar trends in temperature and reaction time were observed; however, as for the alkali charge this trend witnessed the reverse way, which means there needed to be a decrease in the second stage. A maximum brightness of $66.1 \%$ ISO was achieved using $2.5 \% \mathrm{NaOH}$ at $65^{\circ} \mathrm{C}$ for 75 minutes in the second Oxone bleaching. Finally to achieve target brightness, hydrogen peroxide was used and the pulp brightness of $\mathrm{AO}_{\mathrm{X} 1} \mathrm{O}_{\mathrm{X} 2} \mathrm{P}$ sequence was observed to be more than $78 \%$ ISO.

Aging experiments at $105^{\circ} \mathrm{C}$ for $24 \mathrm{hrs} \pm 10 \mathrm{~min}$ showed that alkaline Oxone bleaching stops thermal degradation (brightness reduction). Similarly, the $\mathrm{AO}_{\mathrm{X} 1} \mathrm{O}_{\mathrm{X} 2} \mathrm{P}$ bleaching sequence was found to be effective in regaining some strength drops of acidification stage. Lignin was decreased to a negligible level which, along with the other results, indicates the feasibility of Oxone bleaching as an environmentally favorable alternative TCF bleaching sequence, compared to chlorinated bleaching approaches and also other TCF bleaching sequences.

\section{Conflict of Interests}

The authors declare that there is no conflict of interests regarding the publication of this paper.

\section{Acknowledgments}

Financial support was received from the Ministry of Science, Research and Technology of Iran. The authors express their gratitude to the Pulp and Paper Laboratory of Gorgan University of Agricultural Sciences and Natural Resources.

\section{References}

[1] F. López, M. J. Díaz, M. E. Eugenio, J. Ariza, A. Rodríguez, and L. Jiménez, "Optimization of hydrogen peroxide in totally chlorine free bleaching of cellulose pulp from olive tree residues," Bioresource Technology, vol. 87, no. 3, pp. 255-261, 2003.

[2] B. Bujanovic, R. S. Reiner, S. A. Ralph, and R. H. Atalla, "Polyoxometalate delignification of birch kraft pulp and effect on residual lignin," Journal of Wood Chemistry and Technology, vol. 31, no. 2, pp. 121-141, 2011.

[3] C. W. Dence and D. W. Reeve, Pulp Bleaching: Principles and Practice, Tappi Press, Atlanta, Ga, USA, 1996.

[4] E. Sjostrom, Wood Chemistry, Fundamentals and Applications, 1981.

[5] A. J. Ragauskas, K. M. Poll, and A. J. Cesternino, "Effect of xylanase pretreatment procedures for non-chlorine bleaching," Technical Paper Series 482, Institute of Paper Science and Technology, Atlanta, Ga, USA, 1993.

[6] N. Yaqoob, K. Stack, and K. L. Nguyen, "TCF bleaching of Eucalypt kraft pulp with Oxone," Appita Journal, vol. 63, no. 5, pp. 381-386, 2010.

[7] E. L. Springer, "Delignification of wood and kraft pulp with peroxymonophosphoric acid," Journal of Pulp and Paper Science, vol. 23 , no. 12 , pp. $582-584,1997$.

[8] J. Bouchard, C. Maine, R. M. Berry, and D. S. Argyropoulos, "Kraft pulp bleaching using dimethyldioxirane: stability of the oxidants," Canadian Journal of Chemistry, vol. 74, no. 2, pp. 232237, 1996.

[9] DuPont Oxone, Monopersulfate Compound General Technical Attributes, DuPont, 2008, http://www.oxone.dupont.com/.

[10] E. L. Springer, "Potential uses for Peroxymonosulfste in pulping and bleaching," in Proceedings of the 1989 and 1990 AIChe Forest Products Symposium : November 5-10, 1989, San Francisco, California; November 11-16, 1990, Chicago, Illinois. Atlanta, GA, pp. 113-120, TAPPI press, Atlanta, Ga, USA, 1992.

[11] E. L. Springer and J. D. McSweeny, "Bleaching kraft pulps with peroxymonosulfate and oxygen," in Proceedings of the TAPPI Pulping Conference, pp. 453-457, 1993.

[12] M. N. Dafchahi and H. Resalati, "Evaluation of pre-hydrolyzed soda-AQ dissolving pulp from Populus deltoides using an ODED bleaching sequence," BioResources, vol. 7, no. 3, pp. 32833292, 2012.

[13] C. A. P. Primo and M. G. V. S. Carvalho, "Acid treatment applied to portuguese Eucalyptus globulus kraft pulp before bleaching: effect on quality and hexenuronic acids and metals contents," in Proceedings of the 28th Eucepa Conference, pp. 281-283, Lisboa, Portugal, 2003.

[14] N. Yaqoob, K. Stack, K. J. Cheema, B. Mateen, and I. Rehman, "Oxidative delignification and bleaching of alkaline sulphiteanthraquinone wheat straw pulp," Asian Journal of Chemistry, vol. 23, no. 7, pp. 2845-2851, 2011.

[15] T. Vuorinen, J. Buchert, A. Teleman, and P. Fagerstrom, "Selective hydrolysis of hexenuronic acid groups and its application in ECF and TCF bleaching of Kraft pulps," in Proceedings of the International Pulp Bleaching Conference, p. 43, TAPPI Press, Washington, DC, USA, April 1996.

[16] D. V. Evtuguin, A. I. D. Daniel, and C. Pascoal Neto, "Determination of hexenuronic acid and residual lignin in pulps by UV spectroscopy in cadoxen solutions," Journal of Pulp and Paper Science, vol. 28, no. 6, pp. 189-192, 2002.

[17] G. X. Pan, C. Thomson, and G. J. Leary, "Bleaching of high-yield lignocellulosic pulps with peroxygen reagents," in Oxidative Delignification Chemistry, vol. 785 of ACS Symposium Series, chapter 9, pp. 163-181, ACS, Washington, DC, USA, 2001.

[18] T. Rosenau, A. Potthast, P. Kosma, H. U. Suess, and N. Nimmerfroh, "Chromophores in aged hardwood pulp-their structure and degradation potential," Holzforschung, vol. 61, pp. 656-661, 2007.

[19] P. Bajpai, "Environmentally benign approaches for pulp bleaching," in Developments in Environmental Management, Elsevier, Amsterdam, The Netherlands, 1st edition, 2005.

[20] N. Yaqoob, I. Rehman, K. Chema, S. Hameed, and B. Mateen, "Environmental benign TCF bleaching sequences for AS/AQ wheat straw pulp," United States Patent, Patent no: US 8, 080, 129 b2, 2011.

[21] H. U. Suess, K. Schmidt, and B. Hopf, "How to improve brightness stability of ECF bleached softwood and hardwood kraft pulp," in Proceedings of the 58th Appita Annual Conference and Exhibition Incorporating the Pan Pacific Conference, pp. 493-499, Canberra, Australia, April 2004.

[22] J. L. Colodette, J. L. Gomide, D. L. Júnior, and C. Pedrazzi, "Effect of pulp delignification degree on fiber line performance and bleaching effluent load," BioResources, vol. 2, no. 2, pp. 223 234, 2007.

[23] P. E. G. Loureiro, E. F. Domingues, D. V. Evtuguin, and M. G. V. S. Carvalho, "ECF bleaching with a final hydrogen peroxide stage: impact on the chemical composition of Eucalyptus 
globulus kraft pulps," BioResources, vol. 5, no. 4, pp. 2567-2580, 2010.

[24] M. Ek, G. Gellerstedt, and G. Henriksson, Pulp and Paper Chemistry and Technology, Volume 2, Walter de Gruyter, Bremen, Germany, 1st edition, 2009.

[25] F. Zeinaly, J. Shakhes, M. D. Firozabadi, and A. Shakeri, "Hydrogen peroxide bleaching of CMP pulp using magnesium hydroxide," BioResources, vol. 4, no. 4, pp. 1409-1416, 2009.

[26] R. Berggren, Cellulose degradation in pulp fibers studied as changes in molar mass distributions [Ph.D. thesis], Department of Fibre and Polymer Technology, Royal Institute of Technology, Stockholm, Sweden, 2003.

[27] F. S. Chakar, L. Allison, A. J. Ragauskas, T. J. McDonough, and U. Sezgi, "Influence of hexenuronic acids on U.S. bleaching operations," TAPPI Journal, vol. 83, no. 11, article 62, 2000. 

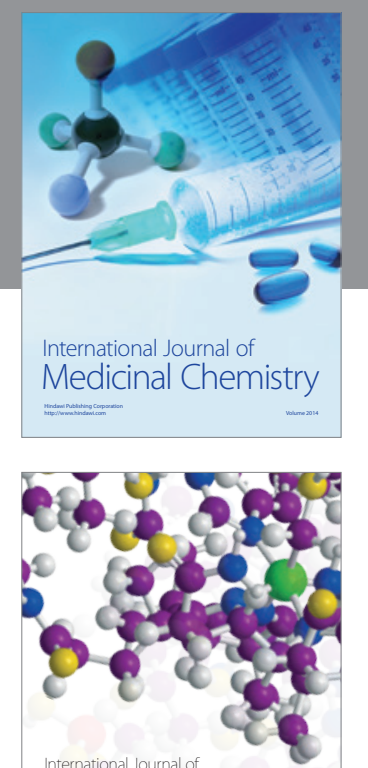

\section{Carbohydrate} Chemistry

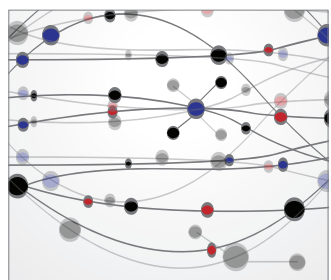

The Scientific World Journal
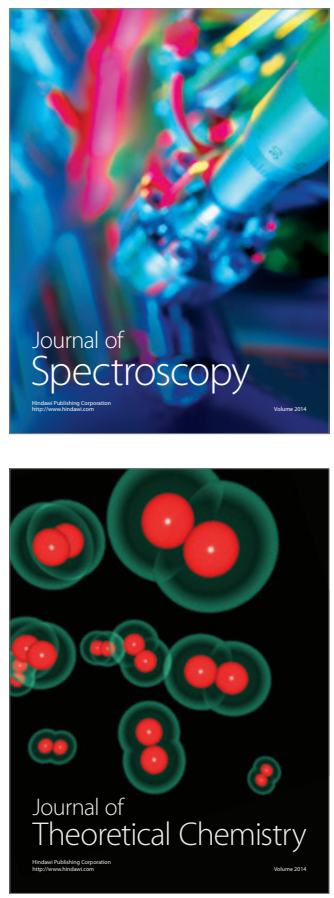
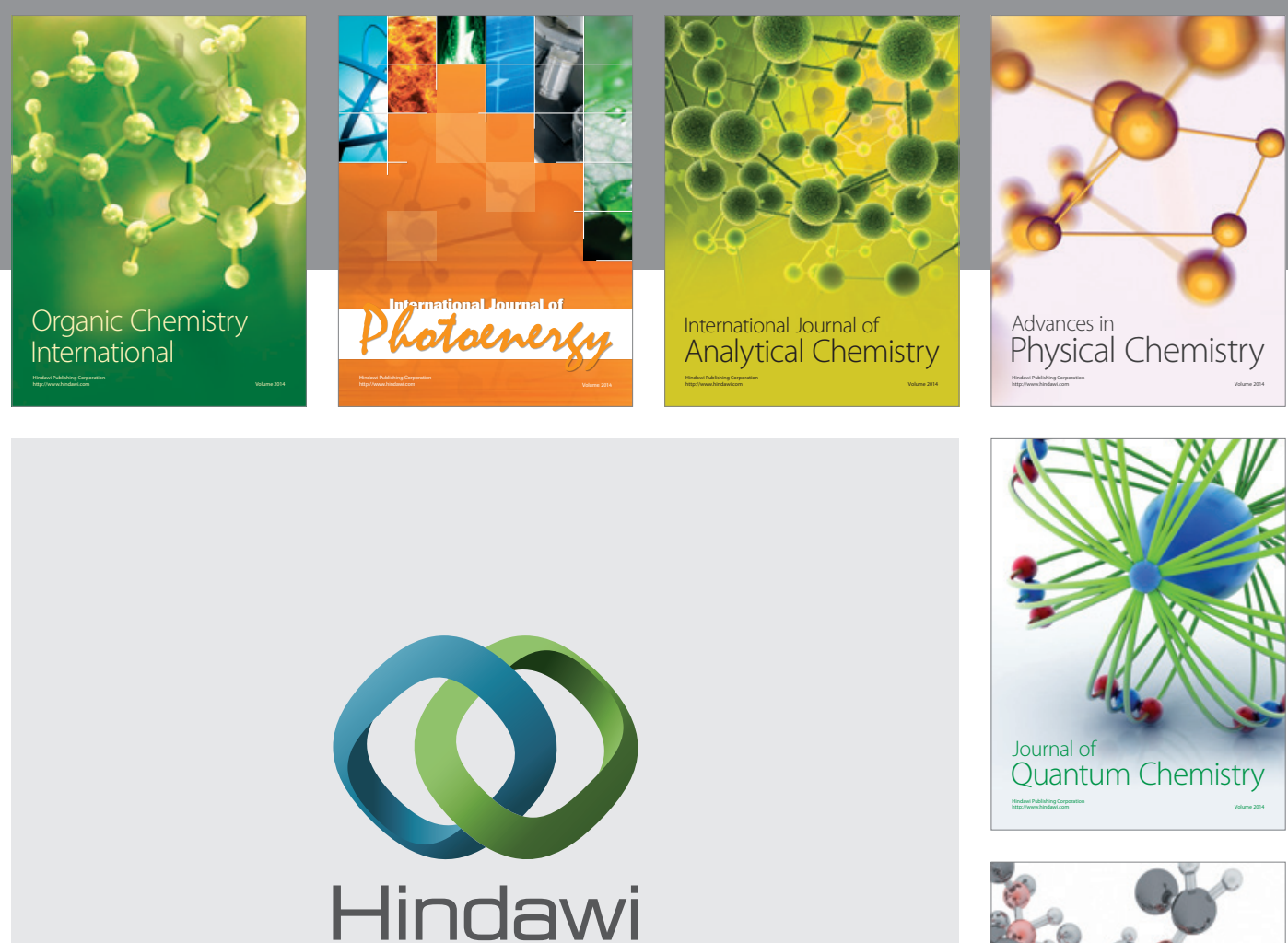

Submit your manuscripts at

http://www.hindawi.com

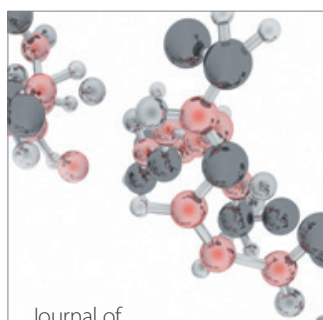

Analytical Methods

in Chemistry

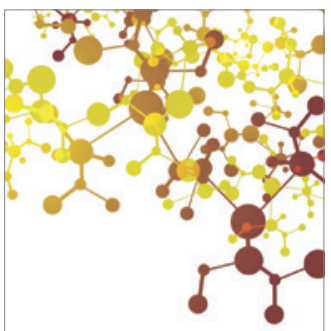

Journal of

Applied Chemistry

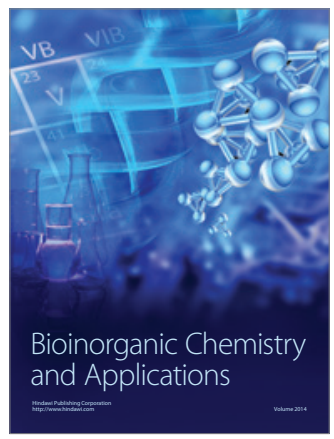

Inorganic Chemistry
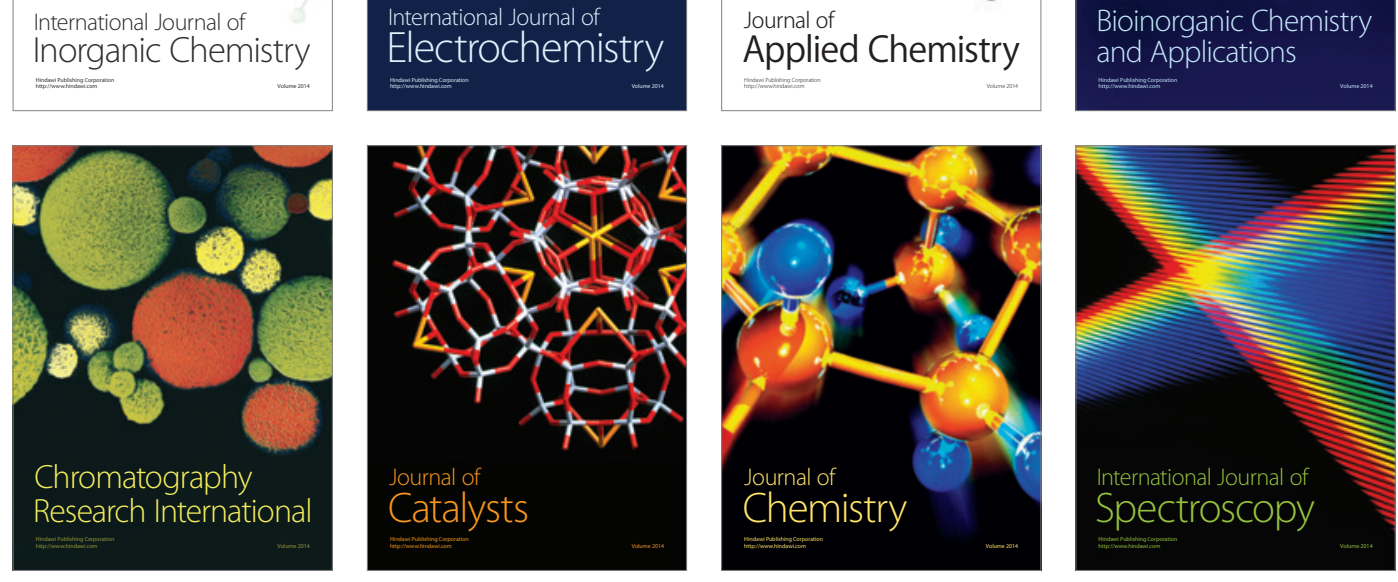